\title{
Evaluating different scenarios for Tradable Green Certificates by game theory approaches
}

\author{
Meysam Ghaffari ${ }^{1} \cdot$ Ashkan Hafezalkotob $^{1}$
}

Received: 29 August 2017 / Accepted: 3 May 2018/Published online: 1 June 2018

(C) The Author(s) 2018

\begin{abstract}
Right now employment of polices and tools to decrease the carbon emission through electricity generation from renewable resources is one of the most important problem in energy policy. Tradable Green Certificate (TGC) is an economics mechanism to support green power generation. Any country has the challenge to choose an appropriate policy and mechanism for design and implementation of TGC. The purpose of this study is to help policy makers to design and choose the best scenario of TGC by evaluating six scenarios, based on game theory approach. This study will be useful for increasing the effectiveness of TGC system in interaction with electricity market. Particularly, the competition between thermal and renewable power plants is modeled by mathematical modeling tools such as cooperative games like Nash and Stackelberg. Each game is modeled by taking into account of the two following policies. The results of the six scenarios and the sensitivity analysis of some key parameters have been evaluated by numerical studies. Finally, in order to evaluate the scenarios we calculated the level of social welfare in the all scenarios. The results of all models demonstrate that when the green electricity share (minimum requirement) increases the TGC price decreases. Moreover, in all scenarios when the minimum requirement is $100 \%$ then the maximum level of social welfare is not met. Also when the minimum requirement is less than $50 \%$, the scenarios with the market TGC price policy have more social welfare in comparison with the scenarios with fixed TGC price policy.
\end{abstract}

Keywords Green electricity · Tradable Green Certificate · Game theory · Mathematical modeling

\section{Introduction}

The policies of energy sector are one of the most effective policies in development of countries. Climate change and energy security are the most important factors in the energy policies, setting regulations and energy models of investment (REN21 2012; Bazilian et al. 2011). It is necessary to reduce the greenhouse gases emissions in order to control the climate change (Buchner and Carraro 2005). Hence, to

Ashkan Hafezalkotob

a_hafez@azad.ac.ir; Hafezalkotob@iust.ac.ir

Meysam Ghaffari

st_m_ghaffari@azad.ac.ir; mghaffari7@yahoo.com

1 Industrial Engineering College, Islamic Azad University, South Tehran Branch, Entezari alley, Oskoui alley, Choobi Bridge, Tehran 1151863411, Iran develop renewable energy many countries have set road map, goals and mandatory targets to reduce greenhouse gases emissions. The share of the renewable energy (RE) should be increased from the current $17-30$ or $75 \%$ or even to $90 \%$ in some countries by 2050. Also, European Union (EU) has set a minimum target of $20 \%$ by 2020 in total energy consumption (GEA 2012; Zhou 2012).

The significant outcome of using the RE will be strengthening the economic growth by creating employment, developing clean environment by reducing carbon emissions, enhancing technological innovation systems and curbing the volatility of fuel prices. On the other hand, RE can boost economic growth and it can mitigate pollutant emissions. Moreover, it can increase the supply adequacy and it might facilitate the access to electricity in order to promote the rural development and social welfare (Tiba et al. 2016; Azuela and Barroso 2011; Fargione et al. 2008). 
One of the most important factors in reducing the carbon emissions is electricity generation from renewable sources. Currently, tendency of different countries to generate electricity from renewable sources is increasing by using TGC systems and feed-in tariff (Tamás et al. 2010).

Many researches have addressed feed-in tariffs. As a case in point, Oderinwale and van der Weijde (2016) used an input-output table to analyze a next-generation energy system to evaluate economic impacts of Japan's renewable energy sector and the feed-in tariff system.

The previous researches indicate that the TGC system has better results in comparison with feed-in tariffs (Ciarreta et al. 2014; Tamás et al. 2010).

The TGC system as an economic mechanism is introduced to supply electricity from RE with the least cost for government. In this system, any entity of electricity supply chain can require a certain share in the production or consumption of electricity from RE (Aune et al. 2010).

In this study, we will model the interaction between thermal and renewable producers in the electricity and TGC markets where the thermal producer is an obligation to supply a certain share of green electricity by buying TGC from renewable producer. The models will be analyzed based on imperfect competitive/cooperative situations like Nash and Stackelberg equilibriums. The impact of minimum requirement and the TGCs price on total electricity and electricity price will be investigated by a numerical study.

The reminder of the paper is organized as follows: Literature review is presented in Sect. 2. Section 3 describes the prerequisites and assumptions. In Sect. 4, profit function of the power plants in electricity and TGC markets is set up. Section 5 presents six scenarios based on the game theory models and TGC pricing policies. Section 6 introduces the pricing system of electricity and TGC in six scenarios. Section 7 discusses the evaluation of policies by a numerical study and sensitivity analysis. Finally, Conclusion is provided in "Appendix" section.

\section{Literature review}

TGCs have been introduced as financial assets and they are allocated to the renewable power plants in exchange for the amount of green electricity generated from renewable sources. The outcome of this would be that the renewable producers will benefit from sale of physical electricity in electricity market and sale green certificates in TGCs market (Farinosi et al. 2012).

TGCs system is usually operates as a market and is based on demand and supply. The demand of TGCs is determined by energy policies and the annual share of electricity production from renewable sources. Obligation can be set on any point of the electricity supply chain such as supplier, transmitter, distributer, retailer and consumer of electricity (except the green electricity producers). This is obligated to purchase a certain share of the TGCs from electricity producers based on the energy policies of every country (Mitchell and Anderson 2000).

Certificates are usually issued by the government and in exchange for $1 \mathrm{MW} / \mathrm{h}$ or higher units or higher produced by the renewable power plant. Renewable power plant can be profitable by selling certificates and physical electricity. TGC market as financial market is created by an interaction between the supplier of TGC (renewable power plant) and demandant of TGC (thermal power plant in this study). As a case in point, Denmark has set obligation on customers (Nielsen and Jeppesen 2003). In this policy, TGCs market creates an interaction between the green electricity producers and electricity consumers where the consumers are obliged to buy certificates or consume a certain proportion of the renewable electricity based on minimum requirement.

The countries may employ different mechanisms to organize the demand certificates by

1. Setting a fixed price at certificates,

2. Creating an obligation at every entity of the electricity supply chain to purchase certificates within a certain period,

3. Establishing a mechanism to tender purchasing certificates,

4. Using a voluntary demand mechanism for certificates (Schaeffer et al. 2000).

In TGC system content, there are a few formal researches (Tamás et al. 2010). By using economic analysis, Jensen and Skytte (2003) modeled the interaction of the electricity market (with the assumption monopolistic competition) and the TGC market (with the assumption of a perfect competition). They showed that relationship between the TGC price and electricity price is linear. With the same method, the polish scheme with regard to its economic functioning and its justification with reference to solve common obstacles for renewable technology deployment was analyzed by Heinzel and Winkler (2011). The results demonstrate that the scheme is not mandatory to solve obstacles on the legal or institutional level. After their liberalization, social acceptance might rather decrease when power price for consumers goes up.

By using the quality methods, Verhaegen et al. (2009) described and analyzed the details of the TGCs system in Belgium. With the same method, Verbruggen and Lauber (2012) evaluated the feed-in tariff and TGC system in three criteria of efficiency, equity and institutional feasibility. Some of the researchers analyzed the TGC system by using the system dynamic method. In recent researches, this method has been used for conceptualizing, analyzing, designing and evaluating issues in energy sectors such as 
energy policy, power pricing, strategies of electricity market, and interaction between electricity and TGC markets (Ahmad and bin Mat Tahar 2014). Ford et al. (2007) predicted the price of certificates to aid green electricity from the wind resources. The results showed that after a few years the wind power exceeds the requirements because in the early years when a market opens the price of TGC will be increased rapidly. Recently, Hasani-Marzooni and Hosseini (2012) modeled the TGC system by employing the system dynamics to identify the potential investment in the wind energy. They showed that the system dynamics can be used as an appropriate tool to investigate TGC market and help the regulatory authorities to choose the appropriate policies in the energy sector.

To analyze the TGC system, a number of mathematical models are used by some researchers. Marchenko (2008) through a simple mathematical model simulated the balance of supply and demand in electricity and the TGC markets. He showed that the TGC system is not an appropriate policy to minimize the negative effects of energy production in the environment. Gürkan and Langestraat (2014) analyzed the renewable energy obligations and technology banding in the UK by a nonlinear mathematical model. They studied three policies to apply the TGC and showed that the obligation target by UK banding policy cannot be achieved necessarily.

Recently Ghaffari et al. (2016) investigated a game theoretical approach research to analyze the TGC system. In this practice, the TGC price is assumed to be constant and will be determined by the government. They demonstrated that the relation between the electricity price and the TGC price is reverse, whereas the relation between the electricity price and the minimum requirement is direct. Also in renewable power plant Stackelberg model, the production of total electricity and the renewable electricity is at the maximum, while the price of electricity is at the minimum.

Game theory is the one of the most important tools in decision-making. Game theory focuses on the interaction among the players in a game by assuming the conditions that each player chooses to rationalize their preferences (Myerson 1991; Jørgensen and Zaccour 2002).

According to game theory, all the players can use from pure or mixed strategies for their own interests. The reaction of an actor in a critical situation in a game can define a pure strategy. Each combination of different player strategies will have a specific payoff for these players. The numbers of the desirability of possible outcomes show the payoffs in the game. These payoffs are dependent on the applied strategies of the players. There are two types of games such as cooperative and noncooperative games. In the first one, the players intend to cooperate with each other for higher economic and environmental benefits. In the second one, the system might reach an equilibrium state (Lou et al 2004).
There is a little comprehensive research about modeling of the TGC system. Most previous studies analyzed the electricity and TGC markets by economic, and a few dynamic system methods investigated the implementation of this policy in a specific country. To the best of our knowledge, almost TGC system has not been analyzed by a game theoretical approach under pricing policies. However, in this study six different scenarios are analyzed based on two common pricing policies in the TGC system to enhance the knowledge of designers and policy makers in designing and deploying the TGC system.

The contributions of this paper are as follows:

1. We analyzed game theory models to achieve appropriate mechanisms to design market structure for TGC market. We showed some outcomes and impacts.

2. We modeled the market structure for electricity and TGC markets in case of imperfect competition Cournot oligopoly and monopoly under fixed and variable TGC price policy.

3. We used social welfare function for evaluating the developed scenarios so policy makers and government will be enable for choice the finest of energy policies.

\section{Prerequisites and assumptions}

We concentrate on the interaction of two producers for simplicity: renewable and thermal power plants. Electricity producers compete in the electricity and TGC market under producer obligation. Thus, thermal power plant is obliged to buy a certain amount of TGCs based on minimum requirement.

The government sets the minimum requirement. We consider two policies for the price of certificates. In the first policy, the price of certificates is fixed and is set by the government. In the second policy, the price of certificates is determined by market conditions and supply and demand mechanisms.

\section{Notations}

In this study, parameters and decision variables are as follows:

\section{Parameters}

$\alpha \quad$ the minimum requirement of renewable electricity, $0 \leq \alpha \leq 1$

$\pi_{R}$ the profit function of renewable producer;

$\pi_{\mathrm{T}} \quad$ the profit function of thermal producer;

$\pi$ the total payoff of centralized producer, $\left(\pi=\pi_{\mathrm{R}}+\pi_{\mathrm{T}}\right)$ 
Table 1 Scenarios of TGC implementation

\begin{tabular}{lll}
\hline Game theory models & Market price of certificate & Fixed price of certificate \\
\hline Nash & NM scenario & NF scenario \\
Stackelberg & SM scenario & SF scenario \\
Cooperative & CM scenario & CF scenario \\
\hline
\end{tabular}

$C_{\mathrm{T}}$ the cost function of thermal producer;

$C_{\mathrm{R}}$ the cost function of renewable producer;

$U$ the consumer utility;

$D$ the function of environmental damages.

\section{Decision variables}

$P_{\mathrm{e}} \quad$ the end-user price of electricity $(\$ / \mathrm{MWh}), P_{\mathrm{e}}>0$;

$P_{\mathrm{c}}$ the price of TGC $(\$ / \mathrm{MWh}), P_{\mathrm{c}}>0$;

$q_{\mathrm{T}}$ the electricity generated from thermal energy (MW), $q_{\mathrm{T}} \geq 0$;

$q_{\mathrm{R}}$ the generated from renewable energy (MW), $q_{\mathrm{R}} \geq 0$;

$Q$ the total amount of electricity (MW), $Q \geq 0\left(Q=q_{\mathrm{T}}+q_{\mathrm{R}}\right)$.

As shown in Table 1, we have modeled six scenarios to implement the TGC system based on the game theory approach and government policies regarding the control price of certificates.

\section{Assumptions}

The following assumptions have been considered in the proposed models:

1. There is no limitation for power plants in consumption of the resources.

2. There is no limitation on the demand and supply electricity and TGCs.

3. There is no excess demand and supply in the electricity and TGCs markets.

4. Parameters are deterministic and they are known in advance.

5. The demand function of TGC is similar to demand function of electricity.

6. In all models, the supply of certificate meets the minimum requirement $\left(q_{\mathrm{R}} \geq \alpha Q\right)$.

\section{Model formulation}

\section{Renewable producer}

In this practice, we adopted profit functions for the power plants by Tanaka and Chen (2013). Renewable power plant can sell the electricity and the TGCs on the electricity and
TGC markets separately. The renewable producer cost $C_{\mathrm{R}}\left(q_{\mathrm{R}}\right)$ is a function of green electricity generated. The cost of the renewable power plant is only dependent on the green electricity generated $q_{\mathrm{R}}$. Therefore, the renewable producer profit maximization problem will be as follows:

$$
\begin{aligned}
\operatorname{Max} & \pi_{\mathrm{R}}=P_{\mathrm{e}} q_{\mathrm{R}}+(1-\alpha) P_{\mathrm{c}} q_{\mathrm{R}}-C_{\mathrm{R}}\left(q_{\mathrm{R}}\right) \\
\text { S.t: } & \\
& q_{\mathrm{R}} \geq 0
\end{aligned}
$$

where $P_{\mathrm{e}}$ is the end user ${ }^{1}$ of each MW of generated electricity, $\alpha$ is the minimum requirement of green electricity and $P_{\mathrm{c}}$ is the price of certificate. This means that a renewable producer can receive $(1-\alpha) P_{\mathrm{c}}$ for each unit in addition to the electricity price. Under the TGC system, a renewable producer would obtain per unit "subsidy" $(1-\alpha) P_{\mathrm{c}}$.

\section{Thermal producer}

Thermal producers can fulfill their obligation by either production of the renewable electricity or buying the TGCs from renewable producer.

Thermal producer cost $C_{\mathrm{T}}\left(q_{\mathrm{T}}\right)$ is a function of the thermal electricity $q_{\mathrm{T}}$.

Therefore, the thermal producer profit maximization problem will be as follows:

$$
\begin{array}{cl}
\text { Max } & \pi_{\mathrm{T}}=P_{\mathrm{e}} q_{\mathrm{T}}-P_{\mathrm{c}} \alpha q_{\mathrm{T}}-C_{\mathrm{T}}\left(q_{\mathrm{T}}\right) \\
\text { S.t: } & \\
& q_{\mathrm{T}} \geq 0
\end{array}
$$

Thermal power plant can receive $P_{\mathrm{e}}$ for each unit of electricity. The thermal producer is obliged to pay for buying the TGC from the renewable producer in order to compensate the unfulfilled requirements. Therefore, the thermal producer under the TGC system virtually pays a per unit "tax" $\alpha P_{c}$ as in Eq. (2). In the developed model, there is just one thermal power plant that is obliged to hold a number of the TGCs equal to $\alpha$ times its production.

\footnotetext{
${ }^{1}$ Amundsen and Nese (2009), discussed the relation of: $P_{\mathrm{e}}=$ wholesale electricity price $+\alpha P_{\mathrm{c}}$ must be established in the competitive equilibrium market with a large number of retailers.
} 


\section{Cost functions}

We adopt cost functions for the power plants by Jensen and Skytte (2003) and for renewable and thermal power plants it can be described as follows:

$$
\begin{aligned}
& C_{\mathrm{R}}\left(q_{\mathrm{R}}\right)=a_{\mathrm{R}} q_{\mathrm{R}}^{2}+b_{\mathrm{R}} q_{\mathrm{R}}+c_{\mathrm{R}} \\
& \mathrm{C}_{\mathrm{T}}\left(q_{\mathrm{T}}\right)=\mathrm{a}_{\mathrm{T}} q_{\mathrm{T}}^{2}+b_{\mathrm{T}} q_{\mathrm{T}}+c_{\mathrm{T}}
\end{aligned}
$$

In Eqs. (1) and (2), it is assumed that $a_{\mathrm{R}}, b_{\mathrm{R}}, a_{\mathrm{T}}, b_{\mathrm{T}}>0$.

\section{Profit maximization problem for power plants}

Following Newbery (1998) and Tamás et al. (2010), we assume that the demand function for electricity is a linear function,

$P_{\mathrm{e}}=\gamma-\beta Q=\gamma-\beta\left(q_{\mathrm{R}}+q_{\mathrm{T}}\right)$,

Meanwhile, $Q=\left(q_{\mathrm{R}}+q_{\mathrm{T}}\right)$ is the total electricity. On the other hand, we assume that the price of electricity is a decreasing function of amount of renewable electricity. Moreover, based on sixth assumption the demand function of TGC is similar to electricity assumed. The inverse demand function of TGC is as follows:

$P_{\mathrm{c}}=\theta-\varphi q_{\mathrm{R}}$

With substitution of Eq. (5) into Eqs. (1) and (2), the profit maximization problem can be formulated as follows.

Renewable producer is given as below:

$$
\begin{aligned}
\operatorname{Max} & \pi_{\mathrm{R}}=\left(\gamma-\beta\left(q_{\mathrm{R}}+q_{\mathrm{T}}\right)\right) q_{\mathrm{R}}+P_{\mathrm{c}} q_{\mathrm{R}}-a_{\mathrm{R}} q_{\mathrm{R}}^{2}-b_{\mathrm{R}} q_{\mathrm{R}}-c_{\mathrm{R}} \\
\text { s.t: } & \\
& q_{\mathrm{R}} \geq 0
\end{aligned}
$$

Thermal producer is given as below:

$\operatorname{Max} \pi_{\mathrm{T}}=\left(\gamma-\beta\left(q_{\mathrm{R}}+q_{\mathrm{T}}\right)\right) q_{\mathrm{T}}-P_{\mathrm{c}} q_{\mathrm{T}}-a_{\mathrm{T}} q_{\mathrm{T}}^{2}-b_{\mathrm{T}} q_{\mathrm{T}}-c_{\mathrm{T}}$ S.t:

$$
q_{\mathrm{T}} \geq 0
$$

Note that with substitution of Eq. (6) into Eqs. (7) and (8), the problems of producers under market TGC price policy will be obtained.

\section{Game theory models}

\section{Noncooperative Nash game}

If no player has anything to gain by changing his strategy, when the other players do not change their strategies, then the set of strategies for all the players and the corresponding payoffs constitute a Nash equilibrium (Lou et al 2004). The
Nash equilibrium is a vector of participation decisions so that no player has an incentive to deviate from his chosen strategy after considering an opponent's choice (Urpelainen 2014). All players have no motivation to exit the equilibrium, because the outcome of this will be reduction in profit of players. Krause et al. (2006) defined the Nash equilibrium as follows:

The strategy profile in a $(n)$ players game of $P^{*}=$ $\left(P_{1}^{*}, \ldots, P_{n}^{*}\right)$ is a Nash equilibrium (NE) if for all $i \in$ $\{1, \ldots, n\}$ there is:

$U_{i}=\left(P_{1}^{*}, \ldots, P_{n}^{*}\right) \geq\left(P_{1}^{*}, \ldots, P_{i-1}^{*}, P_{i}, P_{i+1}^{*}, \ldots P_{n}^{*}\right)$

where $U_{i}$ is the utility function of the $i$ th player.

In this section, we consider a Cournot-NE game under a TGC system.

It can be seen that by solving NE , from Eqs. (7) and (8) $q_{\mathrm{T}}^{*}$ and $q_{\mathrm{R}}^{*}$ will be obtained. Now, with substitution of $q_{\mathrm{T}}^{*}$ and $q_{\mathrm{R}}^{*}$ into $\pi_{\mathrm{R}}$ and $\pi_{\mathrm{T}}$, the maximum profit of the producers $\left(\pi_{\mathrm{R}}^{*}\right.$ and $\left.\pi_{\mathrm{T}}^{*}\right)$ will be reached. Propositions 1 and 2 present the optimum electricity production quantities in Nash equilibrium under fixed TGC price and market TGC price polices, respectively. Subscripts $[\mathrm{NF}]$ and $[\mathrm{NM}]$ denote the equilibrium points in the Nash game under fixed TGC price policy and the market TGC price policy, respectively.

Proposition 1 Under the fixed TGC price policy, the optimum amounts of production for the renewable and thermal producers in the Nash model can be given as below:

$q_{\mathrm{R}[\mathrm{NF}]}^{*}=-\frac{P_{\mathrm{c}}\left(2 \alpha a_{\mathrm{T}}+\alpha \beta-2 a_{\mathrm{T}}-2 \beta\right)+A_{1}}{2 D+3 \beta^{2}}$

$q_{\mathrm{T}[\mathrm{NF}]}^{*}=-\frac{P_{\mathrm{c}}\left(2 \alpha a_{\mathrm{R}}+2 \beta \alpha+\beta\right)+A_{2}}{2 D+3 \beta^{2}}$

where $A_{1}=2 b_{\mathrm{R}} a_{\mathrm{T}}-2 a_{\mathrm{T}} \gamma+2 \beta b_{\mathrm{R}}-\beta b_{\mathrm{T}}-\beta \gamma, A_{2}=2 b_{\mathrm{T}}$ $a_{\mathrm{R}}-2 a_{\mathrm{R}} \gamma+2 \beta b_{\mathrm{T}}-\beta b_{\mathrm{R}}-\beta \gamma, D=2 a_{\mathrm{R}} a_{\mathrm{T}}+2 a_{\mathrm{R}} \beta+2 a_{\mathrm{T}} \beta$.

All propositions have been proven in "Appendix". With substituting the optimal quantities and Cournot TGC price into Eqs. (7) and (8), optimal profit of the power plants can be calculated.

Proposition 2 Under market TGC price policy, the optimal amounts of production for the renewable and thermal producers in the Nash solution can be given as below:

$q_{\mathrm{R}[\mathrm{NM}]}^{*}=\frac{2 \alpha a_{\mathrm{T}} \theta+\alpha \beta \theta+F_{1}}{4 \alpha a_{\mathrm{T}} \varphi+3 \alpha \beta \varphi+F_{2}}$

$q_{\mathrm{T}[\mathrm{NM}]}^{*}=-\frac{\alpha^{2} \theta \varphi-2 \alpha a_{\mathrm{R}} \theta-\alpha b_{\mathrm{R}} \varphi+2 \alpha b_{\mathrm{T}} \varphi-\alpha \gamma \varphi-\alpha \theta \varphi+E_{1}}{4 \alpha a_{\mathrm{T}} \varphi+3 \alpha \beta \varphi+F_{2}}$ 
where $\quad F_{1}=2 b_{\mathrm{R}} a_{\mathrm{T}}-2 a_{\mathrm{T}} \gamma+2 b_{\mathrm{T}} \theta+2 \beta b_{\mathrm{R}}-\beta b_{\mathrm{T}}-\beta \gamma-$ $2 \beta \theta, F_{2}=4 a_{\mathrm{R}} a_{\mathrm{T}}-4 a_{\mathrm{R}} \beta-4 a_{\mathrm{T}} \beta-4 a_{\mathrm{T}} \varphi-3 \beta^{2}-4 \beta$ $\varphi, E_{1}=-2 a_{\mathrm{R}} b_{\mathrm{T}}+2 a_{\mathrm{R}} \gamma+\beta b_{\mathrm{R}}-2 \beta b_{\mathrm{T}}+\beta \gamma-\beta \theta-2 b_{\mathrm{T}}$ $\varphi+2 \gamma \varphi$.

\section{Noncooperative Stackelberg Games}

We investigated a noncooperative structure for interaction between the thermal and renewable producers where the initiative is the possession of one of the power plants, i.e., the leader. This can enforce its strategy on its rival, i.e., the follower. The first move is made by leader to maximize its profit and then in return the follower reacts by choosing the best strategies.

Since the objective of the TGC system is supporting the increasing share of the electricity generated by RE producer, in this research we only examine renewable producer-Stackelberg model where the renewable producer is leader and the thermal power plant is the follower. In this model, the renewable producer first sells its generated electricity in electricity market. Then the follower as thermal producer sells its generated electricity in electricity market and buys certificates from renewable producer. Propositions 3 and 4 present the optimum production of electricity from renewable and thermal producers in Stackelberg equilibrium under fixed TGC price and market TGC price polices, respectively. Subscripts [SF] and [SM] refer to optimal values of Stackelberg models under the fixed TGC price and market TGC price, respectively

Proposition 3 Under fixed TGC price policy, the optimal amount of electricity generated from renewable and fossil sources in renewable producer-Stackelberg model-is:

$q_{\mathrm{R}[\mathrm{SF}]}^{*}=-\frac{P_{\mathrm{c}}\left(2 \alpha a_{\mathrm{R}}+\alpha \beta-2 a_{\mathrm{R}}-2 \beta\right)+E_{2}}{K}$

$q_{\mathrm{T}[\mathrm{SF}]}^{*}=-\frac{P_{\mathrm{c}}\left(2 \alpha a_{\mathrm{R}} \beta+\alpha \beta^{2}-\alpha E_{2}-2 a_{\mathrm{R}} \beta-2 \beta^{2}\right)+\beta E_{2}+K\left(\gamma-b_{\mathrm{T}}\right)}{2 E_{2}\left(\beta+a_{\mathrm{R}}\right)}$

where $\quad E_{2}=2 a_{\mathrm{R}} b_{\mathrm{R}}-2 a_{\mathrm{R}} \gamma+2 \beta b_{\mathrm{R}}-\beta b_{\mathrm{T}}-\beta \gamma, \quad K=$ $4 a_{\mathrm{R}}^{2}+8 a_{\mathrm{R}} \beta+2 \beta^{2}$.

Proposition 4 Under market TGC price policy, the optimal amount of electricity generated from renewable and fossil sources in renewable producer-Stackelberg model-is:

$q_{\mathrm{R}[\mathrm{SM}]}^{*}=\frac{2 \alpha a_{\mathrm{T}} \theta+\alpha \beta \theta+F_{1}}{4 \alpha a_{\mathrm{T}} \varphi+2 \alpha \beta \varphi-\beta^{2}+F_{2}}$

$$
\begin{aligned}
q_{T[S M]}^{*}= & \frac{\left(2 \alpha a_{T} \theta+\alpha \beta \theta+F_{1}\right)(\alpha \varphi-\beta)}{2\left(\beta+a_{T}\right)\left(4 \alpha a_{T} \varphi+2 \alpha \beta \varphi-\beta^{2}+F_{2}\right)} \\
& -\frac{\alpha \theta-b_{T}+\gamma}{2\left(\beta+a_{T}\right)} .
\end{aligned}
$$

\section{Cooperative game}

In this section, a cooperative relationship between thermal and renewable producers is investigated. In this model, power plants collaborate together in electricity and TGCs markets. We investigate this situation to increase our knowledge about how to divide thermal producer capacity to generate in competition with the renewable producer. Summation of Eqs. (7) and (8) gives cooperative model:

$$
\begin{gathered}
\operatorname{Max} \pi=\left(\gamma-\beta\left(q_{\mathrm{R}}+q_{\mathrm{T}}\right)\right) q_{\mathrm{R}}+P_{\mathrm{c}} q_{\mathrm{R}}-a_{\mathrm{R}} q_{\mathrm{R}}^{2}-b_{\mathrm{R}} q_{\mathrm{R}} \\
-c_{\mathrm{R}}+\left(\gamma-\beta\left(q_{\mathrm{R}}+q_{\mathrm{T}}\right)\right) q_{\mathrm{T}} \\
-P_{\mathrm{c}} q_{\mathrm{T}}-a_{\mathrm{T}} q_{\mathrm{T}}^{2}-b_{\mathrm{T}} q_{\mathrm{T}}-c_{\mathrm{T}}
\end{gathered}
$$

S.t:

$$
q_{\mathrm{R}}, q_{\mathrm{T}} \geq 0
$$

A Hessian matrix of $\pi$ in Eq. (18) is: $H=$ $\left[\begin{array}{cc}-2 \beta-2 a_{\mathrm{R}} & -2 \beta \\ -2 \beta & -2 \beta-2 a_{\mathrm{T}}\end{array}\right]$ and the utility function $\pi$ is a concave function on $\left(q_{\mathrm{R}}, q_{\mathrm{T}}\right)$ if and only if the Hessian matrix $H$ is negative definite. Propositions 5 and 6 present the optimum production quantities of green and thermal electricity of producers in cooperative game under fixed TGC price and market TGC price polices, respectively. Subscripts $[\mathrm{CF}]$ and $[\mathrm{CM}]$ denote the optimum values in the cooperative game model under fixed TGC price and market TGC price polices, respectively.

Proposition 5 Since $\left(-2 \beta-2 a_{\mathrm{R}}\right)\left(-2 \beta-2 a_{\mathrm{T}}\right)-$ $(-2 \beta)(-2 \beta)>0$, the optimal amount of electricity generated from renewable and fossil sources in the cooperative game model under fixed TGC price policy will be:

$q_{\mathrm{R}[\mathrm{CF}]}^{*}=-\frac{P_{\mathrm{c}}\left(\alpha a_{\mathrm{T}}-a_{\mathrm{T}}-\beta\right)+B_{1}}{D}$

$q_{\mathrm{T}[\mathrm{CF}]}^{*}=-\frac{P_{\mathrm{c}}\left(\alpha a_{\mathrm{R}}+\beta\right)+B_{2}}{D}$

where $B_{1}=a_{\mathrm{T}} b_{\mathrm{R}}-a_{\mathrm{T}} \gamma+\beta b_{\mathrm{R}}-\beta b_{\mathrm{T}}, B_{2}=a_{\mathrm{R}} b_{\mathrm{T}}-a_{\mathrm{R}} \gamma-$ $\beta b_{\mathrm{R}}+\beta b_{\mathrm{T}}$.

Substituting Eq. (4) into Eq. (18), the problem of profit centralized power plant under market TGC price policy yields: 
Table 2 Price of TGC in six scenarios

\begin{tabular}{lll}
\hline Game models & TGC price policy & \\
\cline { 2 - 3 } & Market price & Fixed price \\
\hline Nash & $P_{\mathrm{c}[\mathrm{NM}]}^{*}=\theta-\frac{\left(2 \alpha a_{\mathrm{T}} \theta+\alpha \beta \theta+F_{1}\right) \varphi}{4 \alpha a_{\mathrm{T}} \varphi+3 \alpha \beta \varphi+F_{2}}$ & $P_{\mathrm{c}[\mathrm{NF}]}^{*}=c t e$ \\
Stackelberg & $P_{\mathrm{c}[\mathrm{SM}]}^{*}=\theta-\frac{\left(2 \alpha a_{\mathrm{T}} \theta+\alpha \beta \theta+F_{1}\right) \varphi}{4 \alpha a_{\mathrm{T}} \varphi+2 \alpha \beta \varphi-\beta^{2}+F_{2}}$ & $P_{\mathrm{c}[\mathrm{SF}]}^{*}=c t e$ \\
Cooperative & $P_{\mathrm{c}[\mathrm{CM}]}^{*}=\theta-\frac{\left(\alpha^{2} \varphi \theta+2 \alpha a_{\mathrm{T}} \theta+\alpha b_{\mathrm{T}} \theta-\alpha \gamma \varphi+G_{1}\right) \varphi}{\alpha^{2} \varphi^{2}+4 \alpha a_{\mathrm{T}} \varphi+F_{2}+3 \beta^{2}}$ & $P_{\mathrm{c}[\mathrm{CF}]}^{*}=c t e$ \\
\hline
\end{tabular}

"cte" represents a fixed value
$\operatorname{Max} \pi=\left(\gamma-\beta\left(q_{\mathrm{R}}+q_{\mathrm{T}}\right)\right) q_{\mathrm{R}}+\left(\theta-\varphi q_{\mathrm{R}}\right) q_{\mathrm{R}}$

$$
\begin{gathered}
-a_{\mathrm{R}} q_{\mathrm{R}}^{2}-b_{\mathrm{R}} q_{\mathrm{R}}-c_{\mathrm{R}}+\left(\gamma-\beta\left(q_{\mathrm{R}}+q_{\mathrm{T}}\right)\right) q_{\mathrm{T}} \\
-\left(\theta-\varphi q_{\mathrm{R}}\right) q_{\mathrm{T}}-a_{\mathrm{T}} q_{\mathrm{T}}^{2}-b_{\mathrm{T}} q_{\mathrm{T}}-c_{\mathrm{T}}
\end{gathered}
$$

S.t:

$$
q_{\mathrm{R}}, q_{\mathrm{T}} \geq 0
$$

A Hessian matrix of the profit function in the TGC market price policy is $H=\left[\begin{array}{cc}2 \alpha \varphi-2 a_{\mathrm{R}}-2 \beta-2 \varphi & \alpha \varphi-2 \beta \\ -2 \beta-2 a_{\mathrm{T}} & -2 \beta-2 a_{\mathrm{T}}\end{array}\right]$ and the utility function in the cooperative model is a concave function on $\left(q_{\mathrm{R}}, q_{\mathrm{T}}\right)$ if and only if the Hessian matrix $H$ is negative definite.

Proposition 6 Since $\operatorname{det}(H)=\left(2 \alpha \varphi-2 a_{\mathrm{R}}-2 \beta-2 \varphi\right)$ $\left(-2 \beta-2 a_{\mathrm{T}}\right)-(\alpha \varphi-2 \beta)\left(-2 \beta-2 a_{\mathrm{T}}\right)>0$, under market TGC price policy the optimal amount of electricity generated from renewable and fossil sources in the cooperative game model are:

$$
\begin{aligned}
& q_{\mathrm{R}[\mathrm{CM}]}^{*}=\frac{\alpha^{2} \theta \varphi+2 \alpha a_{\mathrm{T}} \theta+\alpha b_{\mathrm{T}} \varphi-\alpha \gamma \varphi+G_{1}}{\alpha^{2} \varphi^{2}+4 \alpha a_{\mathrm{T}} \varphi+3 \beta^{2}+F_{2}} \\
& q_{\mathrm{T}[\mathrm{CM}]}^{*}=-\frac{\alpha^{2} \theta \varphi-2 \alpha a_{\mathrm{R}} \theta-\alpha b_{\mathrm{R}} \varphi+2 \alpha b_{\mathrm{T}} \varphi-\alpha \gamma \varphi-\alpha \theta \varphi+G_{2}}{\alpha^{2} \varphi^{2}+4 \alpha a_{\mathrm{T}} \varphi+3 \beta^{2}+F_{2}}
\end{aligned}
$$

where $\quad G_{1}=+2 a_{\mathrm{T}} b_{\mathrm{R}}-2 a_{\mathrm{T}} \gamma-2 a_{\mathrm{T}} \varphi+2 \beta b_{\mathrm{R}}-2 \beta b_{\mathrm{T}}-$ $2 \beta \theta, G_{2}=-2 a_{\mathrm{R}} b_{\mathrm{T}}+2 a_{\mathrm{R}} \gamma+2 \beta b_{\mathrm{R}}+2 \beta b_{\mathrm{R}}-2 \beta b_{\mathrm{T}}-$ $2 \beta \theta-2 b_{\mathrm{T}} \varphi+2 \gamma \varphi$.

Pricing is the most effective profit lever (Dolan and Simon 1996). This is a process for determining what a company will receive in exchange for its products or services. Pricing can be considered in industry, market, and transaction levels. At the industry level, the main focus is on the overall economics of the industry, including price changes of the supply and demand changes of the customer. On the other hand, in the market level the competitive situation of the price in comparison with the value differential of the product to that of the comparative competing products will be considered. Pricing at the transaction level focuses on managing the implementation of discounts away from the reference or the price list which occur both on and off the invoice or receipt.

In this section, the pricing at the electricity market level is considered in oligopoly and monopoly market structures. Oligopoly is a common form of market where a number of firms are in competition with each other. Based on the game theory approach, the Cournot-Nash and CournotStackelberg models are the oligopoly models. The oligopolies are in fact price setters rather than price takers (Perloff 2008). By substituting the optimal amounts of green and black electricity production quantities in the payoff functions of the renewable and black power plants, the optimum prices of the electricity and TGC are achieved in six scenarios. Tables 2 and 3 depict the electricity price and TGC price in each scenario.

\section{Evaluation policies and sensitivity analysis}

\section{Comparison price and production}

In this section, sensitivity analysis is performed by numerical examples to illustrate performance differences between different models.

We present numerical studies by assuming that the marginal costs and other parameters of the cost function in renewable power plant are higher than nonrenewable power plant.

Cost function of the renewable and nonrenewable producers is assumed as below:

$$
\begin{gathered}
C\left(q_{\mathrm{R}}\right)=0.06 q_{\mathrm{R}}^{2}+11 q_{\mathrm{R}}+100 \text { and } \\
C\left(q_{\mathrm{T}}\right)=0.04 q_{\mathrm{T}}^{2}+8 q_{\mathrm{T}}+20 .
\end{gathered}
$$

The price elasticity of the electricity supply and TGC supply is assumed as below: $\beta=0.4$ and $\varphi=0.3$. It is assumed that $\gamma=150$ and $\theta=50$. In fixed TGC price policies, the TGC price is set equal to average of the TGC market prices per different amounts of the minimum quota.

Figure 1 illustrates the changes of total electricity supply, green electricity supply and black electricity supply versus the minimum requirement of green electricity. 


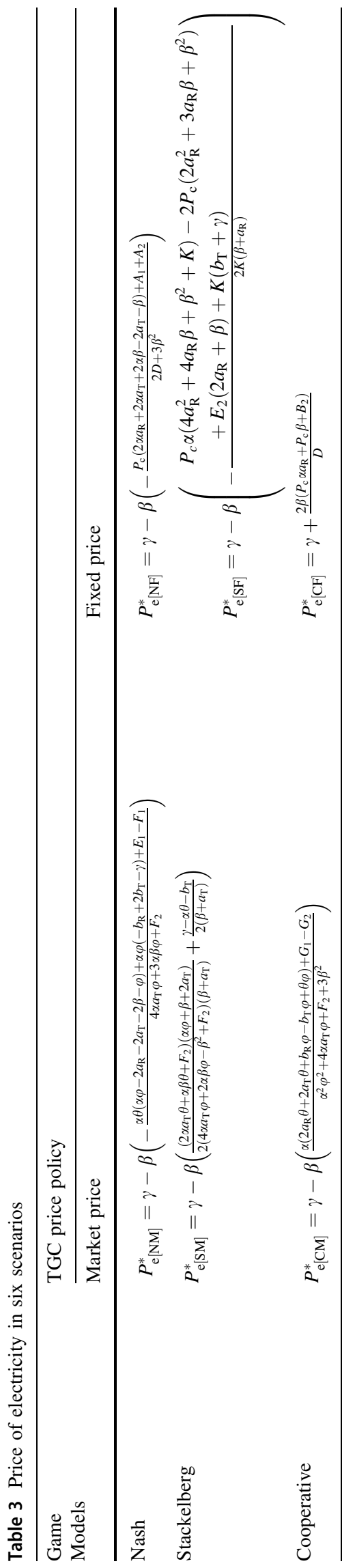

Figure 2 shows the changes of electricity and TGC price versus the minimum requirement of green electricity.

It can be seen from Fig. 1 that in every six scenarios of Table 1 when $\alpha$ increases $Q^{*}$ decreases. However, supply of the green electricity increases in the market price policy and Nash model in the fixed price policy. Moreover, when $\alpha$ increases the black electricity decreases in every six scenarios.

In the CM scenario, when $\alpha$ increases, supply of the total electricity in the first step decreases but then it starts to increase. But in the CF scenario when $\alpha$ increases, supply of total electricity consistently decreases. This means that contrary to the other five scenarios, in the CM scenario when minimum requirement of green electricity $(\alpha)$ is almost $60 \%$ the electricity generated is at minimum amount. The maximum amounts of the green electricity are generated in the $\mathrm{CF}$ scenario. The maximum amounts of the black electricity are generated in the NF scenario and the minimum amounts of the black electricity are supplied in CF scenario. Generally speaking, with changes of the minimum mandatory quota, supply of the total electricity in the SF scenario has the least changes in comparison with the other scenarios.

Figure 1 demonstrates that supply of the total electricity in the SM scenario is greater than the SF scenario consistently. Moreover, the trend of electricity supply in both scenarios is descending with increase in the minimum quota. This result is supported by Jensen and Skytte (2003) and Tamás et al. (2010). Supply of the total electricity in the Nash model of both policies has a descending trend with increase in the minimum quota.

Nevertheless, the total electricity generated in the NF scenario is greater than that of the NM scenario. About the cooperative model, it can be stated that the total electricity generated in the $\mathrm{CF}$ scenario with increase in the minimum quota has absolutely descending trend, whereas the CM scenario shows a convex shape. When the minimum requirement of green electricity is less than $60 \%$, the total electricity generated in the $\mathrm{CF}$ scenario is greater than that of the CM scenario.

Figure 2 shows that there is a reverse relation between the minimum requirement of green electricity and TGC price. However, the relation between the minimum requirement of green electricity and electricity price is direct. In other words, when $\alpha$ increases $P_{\mathrm{e}}^{*}$ increases and $P_{\mathrm{c}}^{*}$ decreases in all scenarios. This matter represents there is a reverse relation between price of TGC and electricity price. This result is supported by Jensen and Skytte (2003), Fristrup (2003), Tamás et al. (2010) and Marchenko (2008).

In the $\mathrm{CM}$ scenario, when $\alpha$ increases, there is a rapid reduction in the price of TGC in comparison with the other 


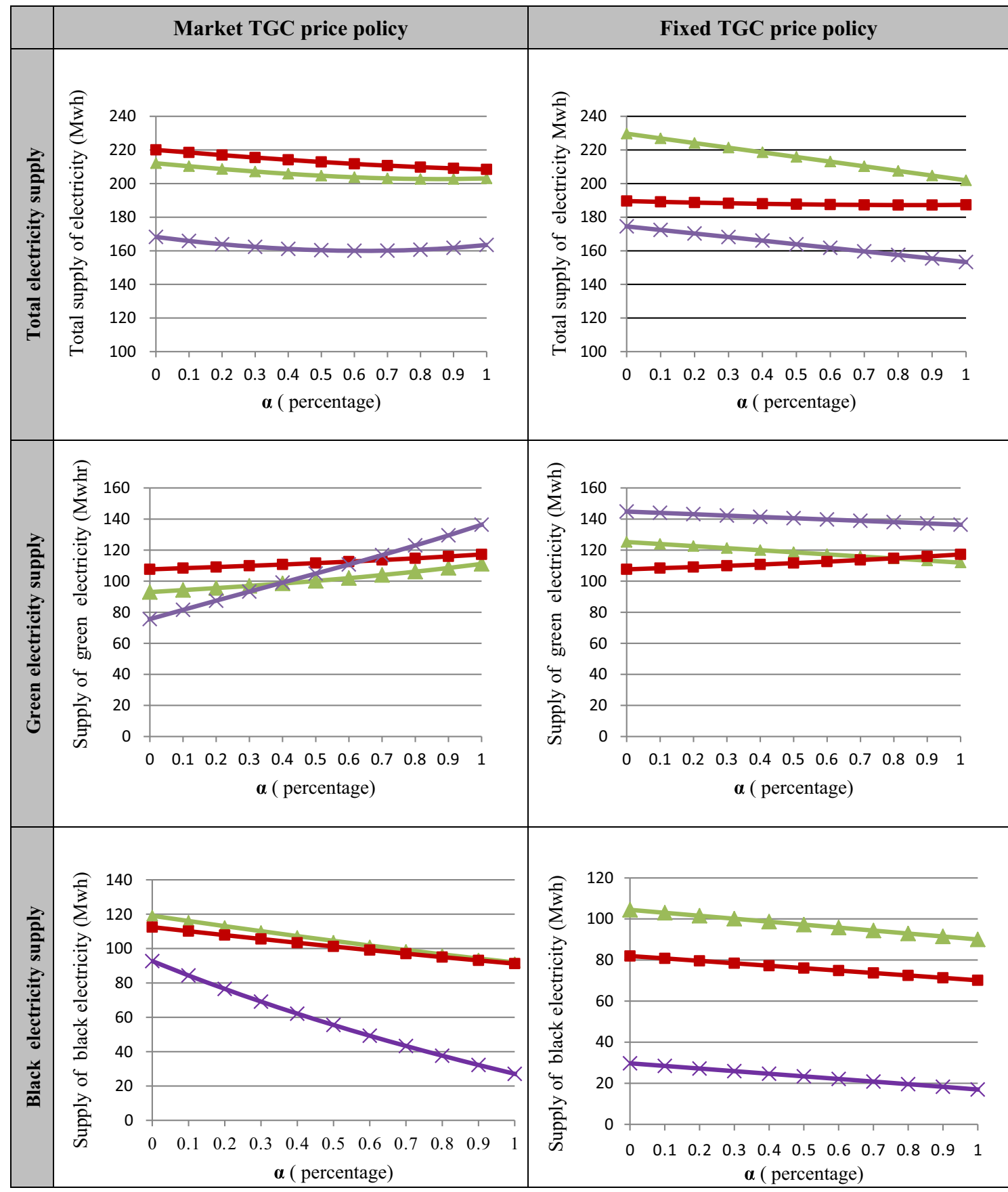

$\triangle$ Nash $\rightarrow$ Stackelberg $\longleftarrow$ Cooperative

Fig. 1 Changes of total, green and black electricity versus minimum quota

scenarios. Among the game theory models, the Stackelberg model in the fixed TGC price results in the minimum electricity price. However, the cooperative model has the maximum electricity price in both fixed TGC price and the market policy price. The price of electricity in the fixed TGC price policy is less than that of the same game theory model in the market TGC price policy.
Changes of payoffs of thermal, renewable and centralized power plants are depicted in Fig. 3. The results of numerical study show that by increasing $\alpha$ total payoff of centralized power plant decreases in all scenarios. Centralized power plant payoff in cooperative model is higher than the other scenarios. By increasing $\alpha$, the payoff of green electricity producer decreases in all scenarios except CM scenario. Note that in Nash and Stackelberg models by 


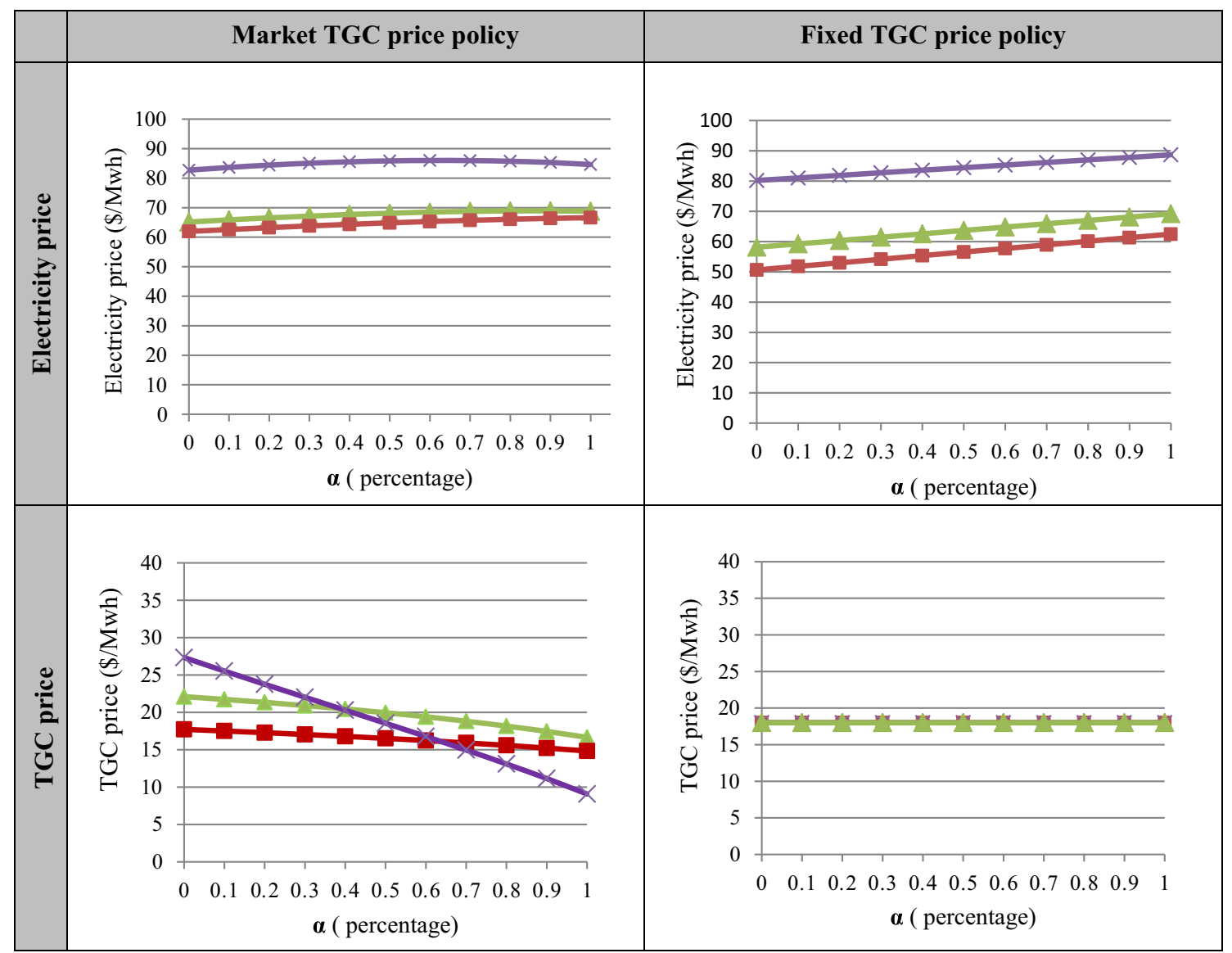

$\therefore$ Nash $\rightarrow$ Stackelberg $\longleftarrow$ Cooperative

Fig. 2 Changes of TGC and electricity price versus minimum quota

increasing $\alpha$ the payoff of green electricity producer decreases under market TGC price policy. Remarkably, by increasing $\alpha$, the payoff of black electricity producer decreases in all scenarios, but in CM scenario, it decreases faster than the other scenarios. It can be concluded that the use of CM scenario will lead to elimination of thermal power plants more quickly.

\section{Social welfare}

Social welfare is an appropriate criterion to evaluate any policy or program (Tamás et al. 2010). To evaluate the six proposed scenarios in this paper, we use the equation of social welfare proposed by Currier (2013). In this case, the social welfare is equal to the total utility minus the all costs including the environmental damages and production costs. Here, $U$ represents the consumer utility and $D$ denotes the function of environmental damages.

$\mathrm{SW}=U(Q)-C\left(q_{\mathrm{T}}\right)-C\left(q_{\mathrm{R}}\right)-D\left(\lambda ; q_{\mathrm{R}}\right)$

Currier and Sun (2014) assumed that $D=q_{\mathrm{R}}^{2} / 2$ and $(Q)=\gamma Q-Q^{2} / 2$. Here $\gamma$ represents the parameter in relation to inverse demand function in Eq. (4), and it is assumed to be equal to 100 . Moreover, it is assumed that the cost function of the green and black power plants is $5 q_{\mathrm{R}}^{2}+30 q_{\mathrm{R}}+100$ and $3 q_{\mathrm{T}}^{2}+10 q_{\mathrm{T}}+20$, respectively, where $\beta=1.2$ and $\varphi=1.2$. It is assumed that: $\gamma=$ $150, \theta=100$ and $\lambda=0.4$. Figure 4 depicts the results of this example in six scenarios.

The evaluation of these polices reveals that in each six scenarios by increasing the minimum quota, social welfare increases at first and decreases later. In other words, in all scenarios the maximum of social welfare does not happen when all the electricity supply is generated from the green sources $(\alpha=100 \%)$. This result is in accordance with Currier (2013) and Currier and Sun (2014). In the fixed TGC price polices, in the first, by increasing of the minimum quota, the social welfare will increase with a faster slope compared with the market TGC price polices.

Generally, when the minimum requirement of renewable energy sources in the electricity supply is less than almost 50\%, the market TGC price polices lead to a higher level of welfare. The welfare in Stackelberg model with the 


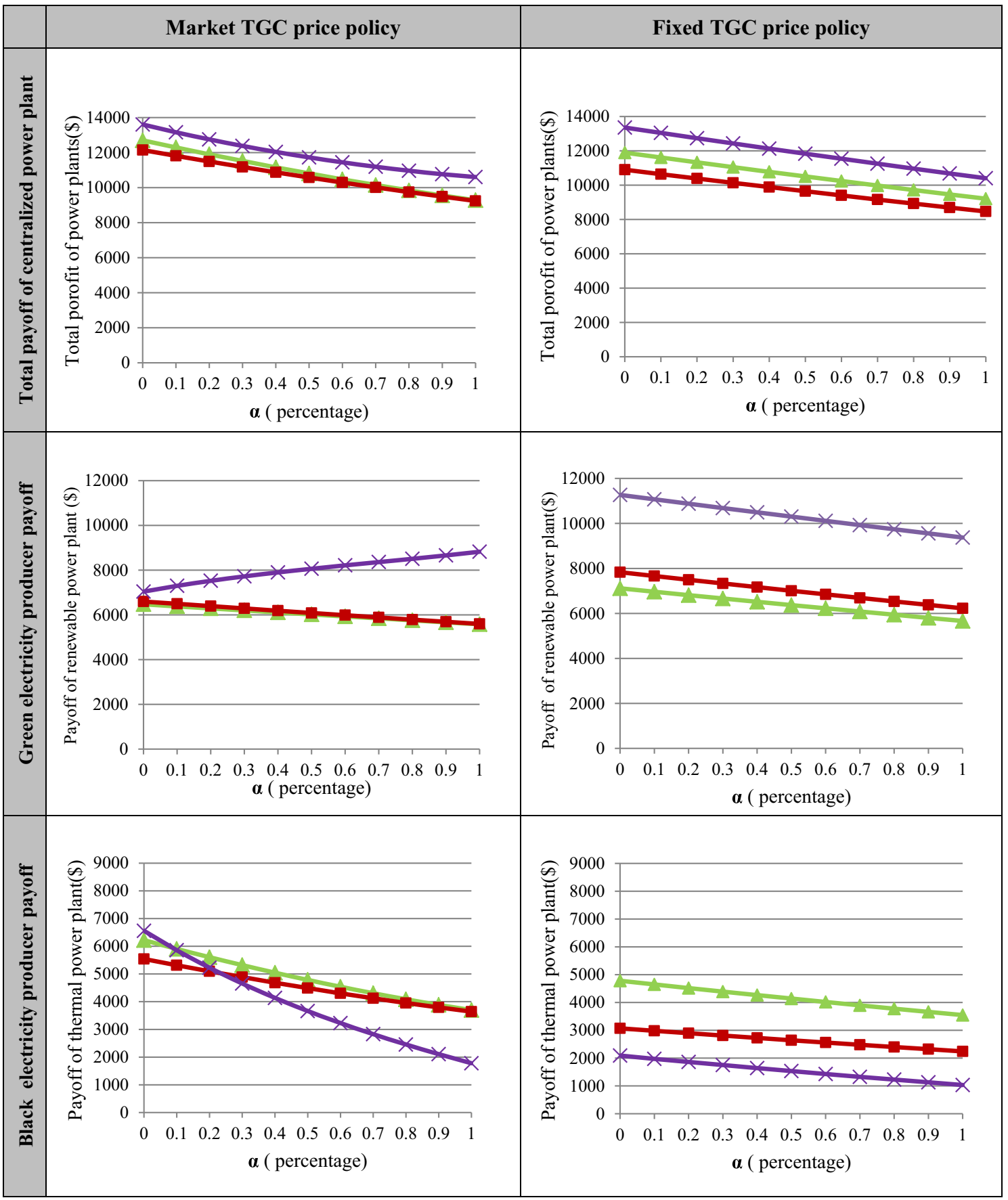

$\triangle$ Nash $\rightarrow$ Stackelberg $\leftarrow$ Cooperative

Fig. 3 Changes of power plants Payoff versus minimum quota

market TGC price policy (SM scenario) is consistently greater than the fixed TGC price policy. But comparing the two control price of certificates policies among other game theory models (Nash and cooperative) shows that there is not a constant trend in terms of welfare created. The maximum welfare is obtained when that market structure follows the Nash or Stackelberg model with the market
TGC price policy (NM and SM scenarios) and $70-80 \%$ of the electricity supply is generated from the RE sources. In contrast, the minimum welfare is obtained when that market structure follows the Nash or Stackelberg model with the fixed TGC price policy (i.e., NF and SF scenarios) when minimum quota is zero $(\alpha=0)$. When $\alpha=0$, the maximum welfare is obtained by CM scenario. Among six 


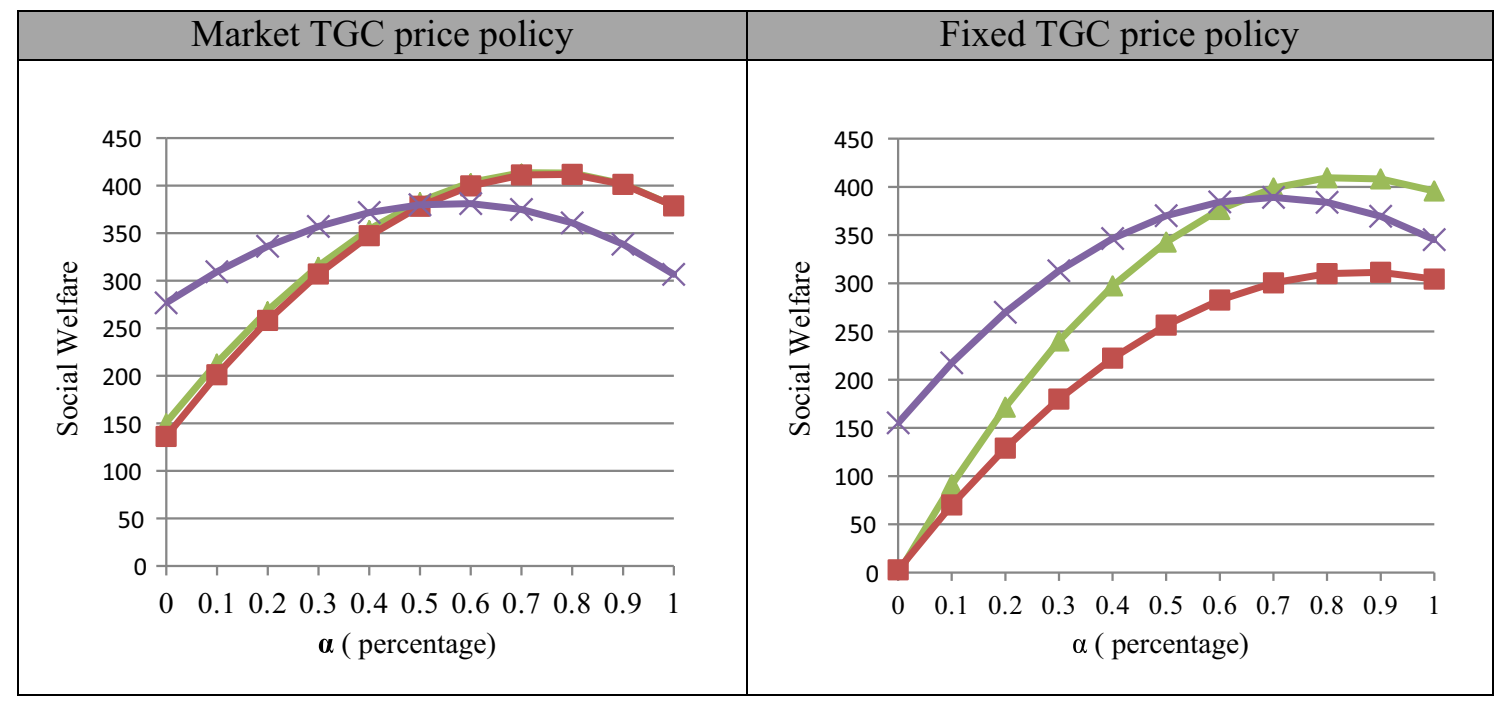

$\longrightarrow$ Nash $\longrightarrow$ Stackelberg $\longrightarrow$ Cooperative

Fig. 4 Comparison of social welfare acquired in each scenario

scenarios, SF scenario creates minimum welfare for all amounts of $\alpha$.

It seems that the results of this practice are useful for private and public investors, energy policy makers, government and other active players in the electricity supply chain. It is an undeniable fact that pricing the TGC is a challenging problem for the government. Therefore, analyzing these models with various scenarios can improve the effectiveness of designing and implementing TGS system.

\section{Conclusion}

This study demonstrates that using market TGC price policy is more beneficial when a country intends to deploy a system of credentials with a share of renewable energy sources less than 50 percent because not only a higher social welfare in this sector is created but also by using this policy the profit of thermal power plants will be decreased with a modest slope and it will not lead to an abrupt withdrawal from the market and lack of power supply. Moreover, if the goal is accelerating the removal of these power plants with abrupt withdrawal, then using the CM scenario is beneficial where the profit of fossil fuels is reduced more steeply. This scenario also will have the lowest power supply among the six scenarios, and it will have the lowest levels of social welfare for $\alpha$ values above $50 \%$.

If a country is so much developed that can provide more than $50 \%$ of its electricity from renewable sources, then using fixed TGC price policy can be beneficial too because at this point it acts like market TGC price policy in creating social welfare. In this policy, the use of NF scenario will be more beneficial in terms of social welfare and high power supply in comparison with three other scenarios.

There are several directions for the future research. Firstly, this study considers the national trade in the electricity market and the TGC system. Game theory formulation of international TGC trade in the internal and external markets is interesting. Secondly, other approaches of game theory to analyze the implementation of the TGC system can be considered. For example, modeling the TGC system in the incomplete information mode by Bayesian models is both interesting and challenging. Thirdly, we only consider the producer's obligation option in the TGC system, but other obligations in the TGC system can also be considered. Finally, no time constraint was considered to validate the certificates. Using the time variables in modeling of the TGC system seems to be useful.

Open Access This article is distributed under the terms of the Creative Commons Attribution 4.0 International License (http://creative commons.org/licenses/by/4.0/), which permits unrestricted use, distribution, and reproduction in any medium, provided you give appropriate credit to the original author(s) and the source, provide a link to the Creative Commons license, and indicate if changes were made.

\section{Appendix}

Proof of Proposition 1 If the second-order derivative for Eq. (7) is negative, the profit function of the green producer will be concave. The first-order derivative for Eq. (7) is: 
$\frac{\partial \pi_{\mathrm{R}}}{\partial q_{\mathrm{R}}}=\left(P_{\mathrm{c}}+\gamma\right)-\left(\beta q_{\mathrm{T}}+2 \beta q_{\mathrm{R}}+2 a_{\mathrm{R}} q_{\mathrm{R}}+b_{\mathrm{R}}\right)=0$.

The second-order derivative for Eq. (7) is as follows:

$\frac{\partial^{2} \pi_{\mathrm{R}}}{\partial^{2} q_{\mathrm{R}}}=-\left(+2 \beta+2 a_{\mathrm{R}}\right)$.

Since the amounts of $\beta$ and $a_{\mathrm{R}}$ are positive, the secondorder derivative is negative $\left(\frac{\partial^{2} \pi_{\mathrm{R}}}{\partial^{2} q_{\mathrm{R}}}<0\right)$.

Therefore, the profit function of the green producer is concave. Similarly, the first-order derivative for Eq. (8) is as follows:

$\frac{\partial \pi_{\mathrm{T}}}{\partial q_{\mathrm{T}}}=\gamma-\left(2 \beta q_{\mathrm{T}}+\beta q_{\mathrm{R}}+P c \alpha+2 a_{\mathrm{T}} q_{\mathrm{T}}+b_{\mathrm{T}}\right)=0$.

The second-order derivative for Eq. (8) yields:

$\frac{\partial^{2} \pi_{\mathrm{T}}}{\partial^{2} q_{\mathrm{T}}}=-\left(2 \beta+2 a_{\mathrm{T}}\right)$.

Since the amounts of $\beta$ and $a_{\mathrm{T}}$ are positive, the secondorder derivative is negative $\left(\frac{\partial^{2} \pi_{\mathrm{R}}}{\partial^{2} q_{\mathrm{R}}}<0\right)$.

Hence, the profit function of the thermal producer will be concave. Solving Eqs. (25) and (27), it follows that the optimal production of power plants is:

$$
\begin{gathered}
q_{\mathrm{R}[\mathrm{NF}]}^{*}=-\frac{P_{\mathrm{c}}\left(2 \alpha a_{\mathrm{T}}+\alpha \beta-2 a_{\mathrm{T}}-2 \beta\right)+A_{1}}{2 D+3 \beta^{2}}, \\
q_{\mathrm{T}[\mathrm{NF}]}^{*}=-\frac{P_{\mathrm{c}}\left(2 \alpha a_{\mathrm{R}}+2 \beta \alpha+\beta\right)+A_{2}}{2 D+3 \beta^{2}} .
\end{gathered}
$$

Proof of Proposition 2 If the second-order derivative of Eq. (7) under market TGC price policy is negative, the profit function of the green producer will be concave. The first-order derivative for Eq. (7) is:

$$
\begin{aligned}
& \frac{\partial \pi_{\mathrm{R}}}{\partial q_{\mathrm{R}}}=q_{\mathrm{R}}\left(-2 \varphi-2 \beta+\alpha \varphi+\varphi \alpha-2 a_{\mathrm{R}}\right) \\
& \quad+\theta+\gamma-\beta q_{\mathrm{T}}-\alpha \theta-b_{\mathrm{R}}=0 .
\end{aligned}
$$

The second-order derivative for Eq. (7) under market TGC price policy is as follows:

$\frac{\partial^{2} \pi_{\mathrm{R}}}{\partial^{2} q_{\mathrm{R}}}=2 \alpha \varphi-2 a_{\mathrm{R}}-2 \beta-2 \varphi=0$.

Since it is assumed that $\varphi, \beta, a_{\mathrm{R}}>0$, and $0 \leq \alpha \leq 1$. We know $\left(\alpha \varphi<a_{\mathrm{R}}+\beta+\varphi\right)$, then the second-order derivative is negative $\left(\frac{\partial^{2} \pi_{R}}{\partial^{2} q_{R}}<0\right)$.
Therefore, the profit function of the green producer is concave. Similarly, the first-order derivative for Eq. (8) is as follows:

$\frac{\partial \pi_{\mathrm{T}}}{\partial q_{\mathrm{T}}}=q_{\mathrm{T}}\left(-2 \beta-2 a_{\mathrm{T}}\right)+q_{\mathrm{R}}(-\beta+\varphi \alpha)+\gamma-\alpha \theta-b_{\mathrm{T}}=0$.

The second-order derivative is as follows:

$\frac{\partial^{2} \pi_{\mathrm{T}}}{\partial^{2} q_{\mathrm{T}}}=-2 a_{\mathrm{T}}-2 \beta=0$.

Since it is assumed that $\beta, a_{\mathrm{T}}>0$, the second-order derivative is negative $\left(\frac{\partial^{2} \pi_{R}}{\partial^{2} q_{R}}<0\right)$.

Therefore, the profit function of the green producer is concave.

Solving Eqs. (29) and (31), it follows that the optimal production of power plants is:

$$
\begin{aligned}
q_{\mathrm{R}[\mathrm{NM}]}^{*} & =\frac{2 \alpha a_{\mathrm{T}} \theta+\alpha \beta \theta+F_{1}}{4 \alpha a_{\mathrm{T}} \varphi+3 \alpha \beta \varphi+F_{2}}, \\
q_{\mathrm{T}[\mathrm{NM}]}^{*} & =-\frac{\alpha^{2} \theta \varphi-2 \alpha a_{\mathrm{R}} \theta-\alpha b_{\mathrm{R}} \varphi+2 \alpha b_{\mathrm{T}} \varphi-\alpha \gamma \varphi-\alpha \theta \varphi+E_{1}}{4 \alpha a_{\mathrm{T}} \varphi+3 \alpha \beta \varphi+F_{2}} .
\end{aligned}
$$

Proof of Proposition 3 To solve the model, $q_{\mathrm{T}}$ is first obtained as a function of $q_{\mathrm{R}}$ and then the first-order derivative is first examined for a profit function of the thermal power plant of Eq. (8). The best response strategy for a thermal power plant is computed as follows:

$q_{\mathrm{T}}=-\frac{\alpha P_{\mathrm{c}}+q_{\mathrm{R}} \beta+b_{\mathrm{T}}-\gamma}{2\left(\beta+a_{\mathrm{T}}\right)}$.

Substituting Eq. (33) into Eq. (7) gives:

$$
\begin{aligned}
\pi_{\mathrm{R}}= & P_{\mathrm{c}} q_{\mathrm{R}}+\left[\gamma-\beta-\left(-\frac{\alpha P_{\mathrm{c}}+\beta q_{\mathrm{R}}+b_{\mathrm{T}}-\gamma}{2\left(\beta+a_{\mathrm{T}}\right)}+q_{\mathrm{R}}\right)\right] q_{\mathrm{R}} \\
& -a_{\mathrm{R}} q_{\mathrm{R}}^{2}-b_{\mathrm{R}} q_{\mathrm{R}}-c_{\mathrm{R}} .
\end{aligned}
$$

The first-order derivative for Eq. (34) yields:

$$
\begin{aligned}
\frac{\partial \pi_{\mathrm{R}}}{\partial q_{\mathrm{R}}} & =P_{\mathrm{c}}-\beta\left(-\frac{\beta}{2\left(\beta+a_{\mathrm{T}}\right)}+1\right) q_{\mathrm{R}}+\gamma \\
& -\beta\left(-\frac{\alpha P_{\mathrm{c}}+\beta q_{\mathrm{R}}+b_{\mathrm{T}}-\gamma}{2\left(\beta+a_{\mathrm{T}}\right)}+q_{\mathrm{R}}\right)-2 a_{\mathrm{R}} q_{\mathrm{R}}-b_{\mathrm{R}}=0 .
\end{aligned}
$$

The profit function of the renewable power plant is concave if the second-order derivative for Eq. (34) is negative. The second-order derivative for the renewable power plant gives:

$\frac{\partial^{2} \pi_{\mathrm{R}}}{\partial^{2} q_{\mathrm{R}}}=-\frac{2 a_{\mathrm{R}} a_{\mathrm{T}}+2 a_{\mathrm{R}} \beta+\beta^{2}}{\beta+a_{\mathrm{T}}}$. 
Regarding the assumptions and parameter values, Eq. (36) is negative. Therefore, the profit function of the renewable power plant is found to be concave. From Eq. (35), it follows that the optimal green electricity production is:

$q_{\mathrm{R}[\mathrm{SF}]}^{*}=-\frac{P_{\mathrm{c}}\left(2 \alpha a_{\mathrm{R}}+\alpha \beta-2 a_{\mathrm{R}}-2 \beta\right)+E_{2}}{K}$.

Substituting $q_{\mathrm{R}[\mathrm{SF}]}^{*}$ into Eq. (33), the optimal black electricity production is:

$$
\begin{aligned}
q_{\mathrm{T}[\mathrm{SF}]}^{*}= & \frac{\left(2 \alpha a_{\mathrm{T}} \theta+\alpha \beta \theta+F_{1}\right)(\alpha \varphi-\beta)}{2\left(\beta+a_{\mathrm{T}}\right)\left(4 \alpha a_{\mathrm{T}} \varphi+2 \alpha \beta \varphi-\beta^{2}+F_{2}\right)} \\
& -\frac{\alpha \theta-b_{\mathrm{T}}+\gamma}{2\left(\beta+a_{\mathrm{T}}\right)} .
\end{aligned}
$$

Proof of Proposition 4 To solve the model, $q_{\mathrm{T}}$ is first obtained as a function of $q_{\mathrm{R}}$ and then the first-order derivative is examined for a profit function of the thermal power plant of Eq. (8) under market TGC price policy; the best response strategy of the thermal power plant is computed as follows:

$q_{\mathrm{T}}=\frac{q_{\mathrm{R}} \alpha \varphi-q_{\mathrm{R}} \beta-\alpha \theta-b_{\mathrm{T}}+\gamma}{2\left(\beta+a_{\mathrm{T}}\right)}$.

Substituting Eq. (37) into Eq. (7) gives:

$$
\begin{aligned}
\pi_{\mathrm{R}}= & \left(-q_{\mathrm{R}} \varphi+\theta\right) q_{\mathrm{R}} \\
& +\left[\gamma-\beta-\left(\frac{q_{\mathrm{R}} \alpha \varphi-\beta q_{\mathrm{R}}-\alpha \theta-b_{\mathrm{T}}+\gamma}{2\left(\beta+a_{\mathrm{T}}\right)}+q_{\mathrm{R}}\right)\right] q_{\mathrm{R}} \\
& -\left(-q_{\mathrm{R}} \varphi+\theta\right) \alpha q_{\mathrm{R}}-a_{\mathrm{R}} q_{\mathrm{R}}^{2}-b_{\mathrm{R}} q_{\mathrm{R}}-c_{\mathrm{R}} .
\end{aligned}
$$

The first-order derivative for Eq. (38) yields:

$$
\begin{aligned}
\frac{\partial \pi_{\mathrm{R}}}{\partial q_{\mathrm{R}}}= & \theta-\beta\left(-\frac{\alpha \varphi-\beta}{2\left(\beta+a_{\mathrm{T}}\right)}+1\right) q_{\mathrm{R}} \\
& +\gamma-\beta\left(-\frac{q_{\mathrm{R}} \alpha \varphi-\beta q_{\mathrm{R}}-\alpha \theta-b_{\mathrm{T}}+\gamma}{2\left(\beta+a_{\mathrm{T}}\right)}+q_{\mathrm{R}}\right) . \\
& +q_{\mathrm{R}}\left(-2 \varphi+\alpha \varphi+\varphi \alpha-2 a_{\mathrm{R}}\right)-b_{\mathrm{R}}=0
\end{aligned}
$$

The profit function of the renewable power plant is concave if the second-order derivative for Eq. (38) is negative. The second-order derivative for the renewable power plant gives:

$\frac{\partial^{2} \pi_{\mathrm{R}}}{\partial^{2} q_{\mathrm{R}}}=-2 \varphi-2 \beta\left(\frac{\alpha \varphi-\beta}{2\left(\beta+a_{\mathrm{T}}\right)}\right)+1+2 \alpha \varphi-2 a_{\mathrm{R}}$.

Regarding the assumptions and parameter values, Eq. (40) will be negative. From Eq. (39), it follows that the optimal green electricity production is:
$q_{\mathrm{R}[\mathrm{SM}]}^{*}=\frac{2 \alpha a_{\mathrm{T}} \theta+\alpha \beta \theta+F_{1}}{4 \alpha a_{\mathrm{T}} \varphi+2 \alpha \beta \varphi-\beta^{2}+F_{2}}$.

Substituting $q_{R[S M]}^{*}$ into Eq. (37), the optimal black electricity production is:

$q_{T[\mathrm{SM}]}^{*}$

$$
=-\frac{P_{c}\left(2 \alpha a_{R} \beta+\alpha \beta^{2}-\alpha E_{2}-2 a_{R} \beta-2 \beta^{2}\right)+\beta E_{1}-b_{T} E_{2}+E_{2} \gamma}{2 E_{2}\left(\beta+a_{R}\right)} .
$$

Proof of Proposition 5 The first-order derivative for the profit function of the power plants in Eq. (25) yields (in the fixed TGC price policy):

$\frac{\partial \pi_{\mathrm{R}}}{\partial q_{\mathrm{R}}}=P_{\mathrm{c}}+\gamma-2 \beta\left(q_{\mathrm{T}}+q_{\mathrm{R}}\right)-2 a_{\mathrm{R}} q_{\mathrm{R}}-b_{\mathrm{R}}=0$,

$\frac{\partial \pi_{\mathrm{T}}}{\partial q_{\mathrm{T}}}=\gamma-2 \beta\left(q_{\mathrm{T}}+q_{\mathrm{R}}\right)-\alpha P_{\mathrm{c}}-2 a_{\mathrm{R}} q_{\mathrm{T}}-b_{\mathrm{T}}=0$.

Solving Eqs. (41) and (42), they give:

$q_{\mathrm{R}[\mathrm{CF}]}^{*}=-\frac{P_{\mathrm{c}}\left(\alpha a_{\mathrm{T}}-a_{\mathrm{T}}-\beta\right)+B_{1}}{D}$.

$q_{\mathrm{T}[\mathrm{CF}]}^{*}=-\frac{P_{\mathrm{c}}\left(\alpha a_{\mathrm{R}}+\beta\right)+B_{2}}{D}$.

Proof of Proposition 6 The first-order derivative for the profit function of the power plants in Eq. (26) yields (in the market TGC price policy):

$$
\begin{aligned}
& \frac{\partial \pi}{\partial q_{\mathrm{R}}}=q_{\mathrm{R}}\left(2 \alpha \varphi-2 a_{\mathrm{R}}-2 \beta-2 \varphi\right)+q_{\mathrm{T}}(\alpha \varphi-2 \beta) \\
& \quad-\alpha \theta-b_{\mathrm{R}}+\gamma+\theta=0, \\
& \frac{\partial \pi}{\partial q_{\mathrm{T}}}=q_{\mathrm{R}}(2 \alpha \varphi-2 \beta)+q_{\mathrm{T}}\left(-2 a_{\mathrm{T}}-2 \beta\right) \\
& \quad-\alpha \theta-b_{\mathrm{T}}+\gamma=0,
\end{aligned}
$$

Since Hessian matrix for this function is negative definite, the profit function is concave. Thus,

Solving Eqs. (43) and (44) yields:

$$
\begin{aligned}
& q_{\mathrm{R}[\mathrm{CM}]}^{*}=\frac{\alpha^{2} \theta \varphi+2 \alpha a_{\mathrm{T}} \theta+\alpha b_{\mathrm{T}} \varphi-\alpha \gamma \varphi+G_{1}}{\alpha^{2} \varphi^{2}+4 \alpha a_{\mathrm{T}} \varphi+3 \beta^{2}+F_{2}}, \\
& q_{\mathrm{T}[\mathrm{CM}]}^{*}=-\frac{\alpha^{2} \theta \varphi-2 \alpha a_{\mathrm{R}} \theta-\alpha b_{\mathrm{R}} \varphi+2 \alpha b_{\mathrm{T}} \varphi-\alpha \gamma \varphi-\alpha \theta \varphi+G_{2}}{\alpha^{2} \varphi^{2}+4 \alpha a_{\mathrm{T}} \varphi+3 \beta^{2}+F_{2}} .
\end{aligned}
$$




\section{References}

Ahmad S, bin Mat Tahar R, (2014) Using system dynamics to evaluate renewable electricity development in Malaysia. Kybernetes 43(1):24-39

Amundsen E, Nese G (2009) Integration of tradable green certificate markets: what can be expected? J Policy Model 31:903-922

Aune F, Dalen H, Hagem C (2010) Implementing the EU renewable target through green certificate markets. Energy Econ 34:992-1000

Azuela G, Barroso L (2011) Design and performance of policy instruments to promote the development of renewable energy: emerging experience in selected developing countries. Energy and mining sector board discussion paper no. 2. The World Bank, Washington, DC

Bazilian M, Hobbs B, Blyth W, MacGill I, Howells M (2011) Interactions between energy security and climate change: a focus on developing countries. Energy Policy 39:3750-3756

Buchner B, Carraro C (2005) Modelling climate policy perspectives on future negotiations. J Policy Model 27:711-732

Ciarreta A, Espinosa MP, Pizarro-Irizar C (2014) Switching from feed-in tariffs to a Tradable Green Certificate market. Interrelat Between Financ Energy 54:261-280

Currier KM (2013) A regulatory adjustment process for the determination of the optimal percentage requirement in an electricity market with Tradable Green Certificates. Energy Policy 62:1053-1057

Currier K, Sun Y (2014) Market power and welfare in electricity markets employing Tradable Green Certificate systems. Int Adv Econ Res 20(2):129-138

Dolan R, Simon H (1996) Power pricing. Free Press, New York

Fargione J, Hill J, Tilman D, Polasky S, Hawthorne P (2008) Land clearing and the biofuel carbon deb. Science 319:1235-1238

Farinosi F, Carrera L, Mysiak J, Breil M, Testella F (2012) Tradable certificates for renewable energy: the Italian experience with hydropower. In: 9th International conference on the European energy market (EEM 2012). IEEE, Florence, pp 1-7

Ford A, Vogstad K, Flynn H (2007) Simulating price patterns for tradable green certificates to promote electricity generation from wind. Energy Policy 35:91-111

Fristrup P (2003) Some challenges related to introducing tradable green certificates. Energy Policy 31(1):15-19

GEA (2012) Global energy assessment: toward a sustainable future. Cambridge University Press, Cambridge

Ghaffari M, Hafezalkotob A, Makui A (2016) Analysis of implementation of Tradable Green Certificates system in a competitive electricity market: a game theory approach. J Ind Eng Int 12(2):185-197

Gürkan G, Langestraat R (2014) Modeling and analysis of renewable energy obligations and technology bandings in the UK electricity market. Energy Policy 70:85-95

Hasani-Marzooni M, Hosseini S (2012) Dynamic interactions of TGC and electricity markets to promote wind capacity investment. IEEE Syst J 6:46-57
Heinzel C, Winkler T (2011) Economic functioning and politically pragmatic justification of tradable green certificates in Poland. Environ Econ Policy Stud 13:157-175

Jensen S, Skytte K (2003) Interactions between the power and green certificate markets. Energy Policy 30:425-435

Jørgensen S, Zaccour G (2002) Time consistency in cooperative differential games. In: Zaccour G (ed) Decision \& Control in Management Science Advances in Computational Management Science, vol 4. Springer. Boston, MA, pp 349-366

Krause T, Beck E, Cherkaoui R, Germond A, Andersson G, Ernst D (2006) A comparison of Nash equilibria analysis and agent based modelling for power markets. Electr Power Energy Syst 28:599-607

Lou HH, Kulkarni MA, Singh A, Huang YL (2004) A game theory based approach for emergy analysis of industrial ecosystem under uncertainty. Clean Technol Environ Policy 6(3):156-161

Marchenko O (2008) Modeling of a green certificate market. Renew Energy 33:1953-1958

Mitchell C, Anderson T (2000) The implication of tradable green certificate for UK. Int J Ambient Energy 21(3):161-168

Myerson R (1991) Game theory: analysis of conflict. Harvard University Press, Cambridge, Chicago

Newbery D (1998) Competition, contracts, and entry in the electricity spot market. Rand J Econ 29:726-749

Nielsen L, Jeppesen T (2003) Tradable Green Certificates in selected European countries-overview and assessment. Energy Policy $31: 3-14$

Oderinwale T, van der Weijde AH (2017) Carbon taxation and feed-in tariffs: evaluating the effect of network and market properties on policy effectiveness. Energy Systems 8(3):623-642

Perloff J (2008) Microeconomics theory and applications with calculus. Pearson, Boston

REN21 (2012) Renewables 2012 global status report. REN21 Secretariat, Paris

Schaeffer GJ (2000) Options for design of tradable green certificate systems. Report/Energy Research Centre of the Netherlands (Netherlands)

Tamás M, Shrestha S, Zhou H (2010) Feed-in tariff and tradable green certificate in oligopoly. Energy Policy 38:4040-4047

Tanaka M, Chen Y (2013) Market power in renewable portfolio standards. Energy Econ 39:187-196

Tiba S, Anis O, Mohamed F (2016) The four-way linkages between renewable energy, environmental quality, trade and economic growth: a comparative analysis between high and middle-income countries. Energy Syst 7:103-144

Urpelainen J (2014) Grid and off-grid electrification: an integrated model with applications to India. Energy Sustain Dev 19:66-71

Verbruggen A, Lauber V (2012) Assessing the performance of renewable electricity support instruments. Energy Policy 45:635-644

Verhaegen K, Meeus L, Belmans R (2009) Towards an international tradable green certificate system - the challenging example of Belgium. Renew Sustain Energy Rev 13:208-215

Zhou H (2012) Impacts of renewables obligation with recycling of the buy-out fund. Energy Policy 46:284-291 